\title{
Cognitive Disorganization in Hippocampus: A Physiological Model of the Disorganization in Psychosis
}

\author{
Andrey V. Olypher, ${ }^{1 \star}$ Daniel Klement, ${ }^{1 \star}$ and André A. Fenton ${ }^{1,2}$ \\ ${ }^{1}$ Institute of Physiology, Academy of Sciences of the Czech Republic, 14220 Prague, Czech Republic, and ²Department of Physiology and Pharmacology, \\ State University of New York, Downstate Medical Center, Brooklyn, New York 11203
}

Cognitive coordination refers to processes that organize the timing of activity among neurons without altering individual discharge properties. Coordinating processes allow neural networks to coactivate related representations and prevent the coactivation of unrelated representations. Impaired cognitive coordination, also called cognitive disorganization, is hypothesized to be the core deficit in the disorganized syndrome of schizophrenia (Phillips and Silverstein, 2003), a condition characterized by hallucinations, disorganization, and thought disorder. This disorganization hypothesis is based on the observation that schizophrenic subjects are impaired at segregating relevant and irrelevant stimuli and selectively using associations between relevant cues. We report that injecting the neural activity blocker tetrodotoxin (TTX) into one hippocampus persistently coactivated pyramidal cells in the uninjected hippocampus that initially discharged independently. In accord with the definition of cognitive disorganization, pyramidal cell firing rates only changed for 15 min and did not accompany the coactivation. The TTX-induced coactivity was maximal at gamma periods, consistent with altered gamma oscillations and disorganization in schizophrenia. A network model confirmed that increasing the coupling of weakly associated cells impairs the selective activation and inhibition of stored spatial representations. This TTX-induced cognitive disorganization correctly predicted that the same TTX injection selectively impaired the ability of rats to segregate relevant associations among distal spatial stimuli from irrelevant local stimuli (Wesierska et al., 2005). The TTX-induced coactivity of hippocampal pyramidal cell discharge has construct and predictive validity as a physiological model of psychosis-related disorganization.

Key words: cognitive coordination; cognitive disorganization; reversible lesion; dynamic grouping; parasitic attractor; schizophrenia

\section{Introduction}

The brain selectively activates and suppresses representations it encodes. This neural coordination has been called cognitive coordination. It is defined as the set of neural processes that control the timing of spiking among cells without changing individual response properties (Phillips and Singer, 1997; Tononi and Edelman, 2000; Phillips and Silverstein, 2003). The coordination idea developed from the binding problem (von der Malsburg, 1981). If bound stimulus features were represented by cell assemblies (Hebb, 1949), then without segregation, coactivation of overlapping assemblies could lead to false, inappropriate, or confused activations of neural representations (von der Malsburg and Schneider, 1986). One proposed mechanism of segregation is desynchronization on the timescale of gamma oscillations (Singer, 1999; Engel et al., 2001).

Cognitive coordination is inferred when people distinguish

Received Sept. 24, 2004; revised Nov. 7, 2005; accepted Nov. 7, 2005.

This work was supported by the European Commission (QLG3-CT-1999-00192) in the framework of Academy of Sciences of the Czech Republic Grant 5011922 and by the Ministry of Education, Youth, and Sports of the Czech Republic, LC554.

${ }^{*}$ A.V.O. and D.K. contributed equally to this work.

Correspondence should be addressed to André Fenton, Department of Physiology and Pharmacology, State University of New York, Downstate Medical Center, 450 Clarkson Avenue, Brooklyn, NY 11203. E-mail: afenton@downstate.edu.

A. V. Olypher's present address: Biology Department, Emory University, Atlanta, GA 30322.

DOI:10.1523/JNEUROSCI.2064-05.2006

Copyright $\odot 2006$ Society for Neuroscience $\quad$ 0270-6474/06/260158-11\$15.00/0 between relevant and irrelevant stimuli to group the relevant stimuli into a coherent percept according to contextual demands. If instructed to identify words, given Figure 1, one is likely to segregate the relevant letters from the numbers and associate the central symbol with the letters to form the word "cable." The central symbol is perceived as the letter " $\mathrm{B}$ " or the number 13 depending on whether words or number sequences are the target. We use "subgrouping" to refer to segregating relevant from irrelevant stimuli and selectively using associations among the relevant stimuli.

Schizophrenic subjects are especially impaired in subgrouping tasks (Silverstein et al., 2000; Uhlhaas et al., 2004), suggesting impaired cognitive coordination, also called cognitive disorganization, is the core deficit in disorganized schizophrenia (Phillips and Silverstein, 2003), a condition characterized by hallucinations, disorganization, and thought disorder. In strong support of the proposal, gamma synchrony is altered in the electroencephalogram (EEG) of schizophrenic subjects (Kwon et al., 1999; Spencer et al., 2003). The alterations positively correlated with the severity of hallucinations, conceptual disorganization, and thought disorder (Spencer et al., 2004).

A rat study provided indirect evidence that injecting the neural activity blocker tetrodotoxin (TTX) into one hippocampus specifically impaired cognitive coordination (Wesierska et al., 2005). Rats on a continuously rotating arena were challenged to subgroup environmental stimuli into relevant, stationary room 


\section{2 \\ CABLE \\ 14}

Figure 1. Example to illustrate subgrouping and contextual modulation. If the goal is to identify a word, one segregates the irrelevant numbers 12 and 14 from the other symbols and groups the relevant letters with the central symbol interpreted as a " $\mathrm{B}$ " to form the word "cable." The meaning of the central symbol as a number or a letter is determined by the context in which it is being interpreted.

cues distinct from rotating cues. They had to represent space using stationary cues to avoid the region of the room where there was foot shock. The TTX injection selectively impaired avoidance in this task but not in tasks that did not require subgrouping to selectively associate shock with the current location. Although impaired cognitive coordination explained the results, impaired memory, navigation, or behavioral inhibition could not. We hypothesized the TTX injection impaired cognitive coordination in the uninjected hippocampus.

The present study tested the prediction that the TTX injection changed the timing of discharge among hippocampal neurons while preserving firing rates. We avoided confounding the TTXinduced dynamic changes in discharge with those associated with the rat's motor (Ranck, 1973; O'Keefe and Recce, 1993; Harris et al., 2003), cognitive (Olypher et al., 2002; Ferbinteanu and Shapiro, 2003), or perceptual activity (Gothard et al., 1996a,b; Rotenberg and Muller, 1997) by studying the electrophysiological effects of the TTX injection in urethane-anesthetized rats.

Parts of this paper have been published previously (Olypher et al., 2003).

\section{Materials and Methods}

Electrophysiology. All procedures met institutional and National Institutes of Health guidelines. Rats were mounted in a stereotaxic instrument under urethane $(1.25 \mathrm{~g} / \mathrm{kg})$ anesthesia, which was supplemented as necessary. A 30 gauge cannula used for intrahippocampal injections in awake rats (Fenton et al., 1998; Cimadevilla et al., 2001) was lowered into one hippocampus with a micromanipulator. The same injection site (relative to bregma: anteroposterior, -3.5 ; mediolateral, \pm 2.6 ; dorsoventral, -3.5$)$ and similar procedures were used as in the behavioral experiments (Cimadevilla et al., 2001; Wesierska et al., 2005). TTX (5 ng/ $\mu \mathrm{l}$ saline) or saline was injected during 1 min unless stated otherwise. The electrophysiological methods were only slightly modified from those used to record from awake rats (Fenton and Muller, 1998; Zinyuk et al., 2000). Instead of implanting tetrodes in microdrives, the tetrodes were lowered to the recording targets by stereotaxic micromanipulators.

Single unit analyses. Single units with long duration action potentials (APs) $(>350 \mu \mathrm{s})$ and low $(<1 \mathrm{AP} / \mathrm{s})$ firing rates were distinguished from those with brief action potentials $(<350 \mu \mathrm{s})$ and high $(>1 \mathrm{AP} / \mathrm{s})$ firing rates, with criteria corresponding to the putative classification of hippocampal pyramidal cells and interneurons, respectively (Ranck, 1973) (see Fig. 3). Only recordings in which action potential waveforms were stable for $>2 \mathrm{~h}$ were analyzed ( 20 of 26 rats). Data were divided into 5 min intervals relative to the TTX injection. Changes were measured relative to baseline taken as the value from the $5 \mathrm{~min}$ immediately before injection.
The correlations between the discharge of pairs of simultaneously recorded cells were calculated. Spike counts in fixed duration time bins were computed and the nonparametric Kendall's correlation coefficient $\tau$ (Press et al., 1993) was calculated. The time bin durations were 5, 10, 25, $50,100,250$, and $500 \mathrm{~ms}$.

Spectra of local field potentials (LFPs) were analyzed for power in the delta $(2-3 \mathrm{~Hz})$, theta $(4-10 \mathrm{~Hz})$, beta $(10-25 \mathrm{~Hz})$, gamma $(40-80 \mathrm{~Hz})$, and sharp wave-associated ripple $(100-250 \mathrm{~Hz})$ frequency bands relative to the power between 1-300 Hz. All data are reported as averages \pm SEM.

Neural network model. A Hopfield-type network was adopted (Rolls et al., 2002) to model the conditions requiring cognitive coordination of dissociated room and arena spatial information:

$$
\begin{array}{r}
\tau \frac{d h_{i}}{d t}=-h_{i}(t)+\sum_{j=1}^{N}\left(w_{i j}-w^{\mathrm{NH}}\right) \times r_{j}(t)+I_{i}(t), \\
r_{i}(t)=\frac{1}{1+\exp \left(-2 \beta\left(h_{i}(t)-\alpha_{i}\right)\right)}, \\
\alpha_{i}= \begin{cases}\alpha^{\mathrm{HIGH}}, & r_{i}(t-\delta t)<\gamma, \\
\alpha^{\mathrm{LOW}}, & r_{i}(t-\delta t) \geq \gamma,\end{cases}
\end{array}
$$$$
1 \leq i \leq N
$$

where $h_{i}(t)$ and $r_{i}(t)$ represent, respectively, the activation and the firing rate of the $i$ th cell, $\tau=10 \mathrm{~ms}, \alpha^{\mathrm{HIGH}}=0, \alpha^{\mathrm{LOW}}=-2.5, \beta=3.5, \gamma=0.5$, $w^{\mathrm{INH}}=0.32, \delta=0.1 \mathrm{~ms}$, and $N=632$.

External input $I_{i}(t)$ was either absent or it set the discharge of the cell to a rate corresponding to the rat's location in the firing field of the cell. Firing fields were modeled as two-dimensional Gaussians:

$$
r_{i}(t)=p_{i} \times a_{i} \exp \left(-\left\|f_{i}-x^{\mathrm{RAT}}(t)\right\|^{2} / 2 \sigma_{i}^{2}\right) .
$$

Here, $a_{i}=0.9, \sigma_{i}=10 \mathrm{~cm}$ for all of the cells, $\|\times\|$ is the standard Euclidian distance, $f_{i}$ and $x^{\mathrm{RAT}}$ are the locations of the firing field center of the cell and the rat, respectively. The firing fields of half the cells were defined in the coordinate frame of the $\operatorname{room}\left(i=1, \ldots, N_{\text {room }} ; N_{\text {room }}=\right.$ $316)$. For these "room cells," both $f_{i}$ and $x^{\text {RAT }}$ in Equation 4 were specified in room coordinates. The other half $\left(N_{\text {room }}+1 \leq i \leq N ; N=632\right.$; "arena cells") had fields defined in the coordinate frame of a constantly rotating arena (1 rpm).

Without external input $\left(p_{i}=0\right)$, activity of a cell was determined by the activity of all of the cells in the network in accord with Equations 1-3. When external input corresponded to room locations, $p_{i}$ values for $90 \%$ of randomly chosen room cells were set to 1 for as long as the input lasted and 0 otherwise. When external input corresponded to arena positions, $p_{i}$ values for $90 \%$ of randomly chosen arena cells were set to 1 . In the case of the input representing both frames, $p_{i}$ values were nonzero for some room and arena cells. For example, in Figure $7 \mathrm{C}, p_{i}$ values were equal to 0.55 for $90 \%$ of randomly chosen room cells and $p_{i}$ values were equal to 0.45 for $90 \%$ of randomly chosen arena cells. For all of the other cells in the network, $p_{i}$ values were equal to zero.

The weights $w_{i j}$ of connections between cells with fields in the same frame were defined to be strong for pairs of cells with adjacent firing field centers and weak for pairs of cells with distant firing field centers: $w_{i j}=$ $\exp \left(-\left\|f_{i}-f_{j}\right\|^{2} / 100\right), 1 \leq i, j \leq N_{\text {room }}$, or $N_{\text {room }}+1 \leq i, j \leq N$. The weights between room and arena cells were relatively weak, $w_{i j}=\varsigma$, where $\varsigma$ was a random number from the interval $(0,0.25)$. To study the effect of randomly increasing excitatory connections in the network, the weights were corrupted according to one of two models:

$$
\begin{gathered}
w_{i j}^{(1)}=w_{i j}+p \times \eta, \\
w_{i j}^{(1)}=w_{i j}+p \times\left(1-w_{i j}\right) \eta,
\end{gathered}
$$

where $p$ set the magnitude of the maximal change, and $\eta$ was a random number from the interval $(0,1)$. For the "symmetric" version of the network, we required not just the usual symmetry of weights $w_{i j}=w_{j i}$ for $1 \leq i \leq j \leq N$, but also the identity of weights between the room cells and

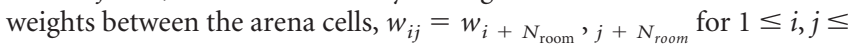


$N_{\text {room }}$, to balance both representations. The difference between the symmetrized and original weights was small and random. Because of that, in accord with theory (Amit, 1989), the networks with symmetrized weights behaved similar to the networks with nonsymmetric weights. For the symmetric network, we calculated the energy function as defined in Hopfield (1984) and made sure that the stabilization of network activity corresponded to a monotonic decrease of the energy function toward a local minimum.

To assess what magnitudes of weight corruption $p$ caused failures of the network to switch from the representation of one location to the representation of another, we chose a set of seven distributed test locations separated by different distances and angles. Inputs corresponding to locations were presented to the network for $25 \mathrm{~ms}$. The network activity was tested $900 \mathrm{~ms}$ after the input presentation. The stability of the network was measured by the distance between the vector of rates at 890 and $900 \mathrm{~ms}$ after input presentation. If the distance normalized by the length of the vector of activity at $890 \mathrm{~ms}$ was $<1 \%$, the network was considered to be stable. The simulations showed that until a very high level of network corruption, $900 \mathrm{~ms}$ was sufficient for the network to stabilize. The values of $p$ from 0 to 0.4 with the step 0.01 were tested. For each value of $p, 10$ independent tests were run. For each test, a new set of weights was generated according to Equation $5 \mathrm{a}$ or $5 \mathrm{~b}$, and the network was run with the inputs corresponding to the same sequence of test locations. At each testing point, the normalized distances of the network activity from the activity of the "intact" tuned network were calculated. Failures to switch from representing one location to another revealed themselves as sharp increases in both the average and variance of normalized distances. The critical regions were double-checked by direct visualization of the maps of ensemble activity (see Fig. 7).

\section{Results}

\section{TTX blocked neural discharge in the injected hippocampus} for hours

Discharge was recorded from dorsal hippocampus $\sim 1 \mathrm{~mm}$ from the injection site $(n=3)$. The simultaneous discharge in the ventral hippocampus (approximately anteroposterior, 6; mediolateral, 5; and dorsoventral, 7) was also recorded. As expected, within 5-7 min of the injection, a time corresponding to the diffusion of TTX that was characterized in the midbrain (Zhuravin and Bures, 1991), action potentials could not be detected at the dorsal site (Fig. $2 A$ ). Activity at the ventral site was silenced 30-40 min after injection. Activity at the ventral site returned suddenly after $\sim 200 \mathrm{~min}$. In contrast, activity at the dorsal site gradually increased starting $\sim 240 \mathrm{~min}$ after the injection. Spontaneous firing at the dorsal site did not return to baseline values even after $7 \mathrm{~h}$.

LFPs in the injected dorsal hippocampus were diminished at all frequencies immediately after TTX injection. It took $\sim 1 \mathrm{~h}$ for power in the gamma band to settle to its new steady state. From $\sim 3 \mathrm{~h}$ after the injection, power in the theta band began to restore (Fig. 2B). The injection only reduced LFPs in the ventral hippocampus on the injected side for $\sim 10 \mathrm{~min}$. Power then recovered and even increased between the theta and gamma frequencies (Fig. 2C).

\section{Firing rates in the uninjected hippocampus}

Saline injection did not change firing rates (Fig. 3A) but TTX injection increased pyramidal cell discharge in the uninjected hippocampus if the cells were active before the injection. Pyramidal cells that were silent before the injection began to discharge (Fig. 3B). Wilcoxon comparisons of the rates in $250 \mathrm{~ms}$ bins 15 min before and up to $15 \mathrm{~min}$ after TTX was injected indicated that the rates of $41 \%$ of 73 pyramidal cells significantly increased. TTX increased the rates of units $(n=63)$ that were active $5 \mathrm{~min}$ before TTX injection by $400 \%$. Rates returned to baseline levels

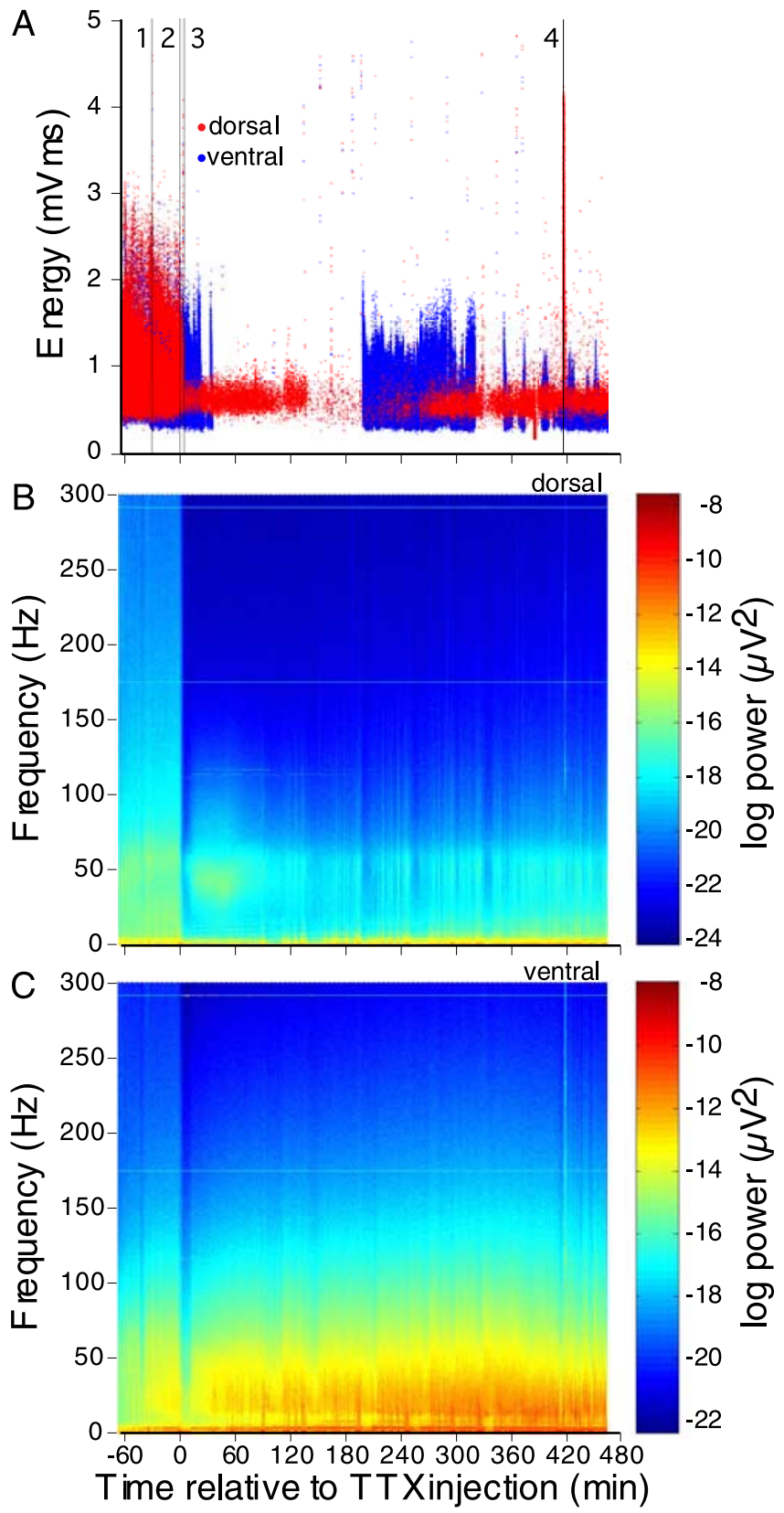

Figure 2. Effect of unilateral TTX injection on the injected hippocampus. A, TTX blocked extracellular activity in the injected hippocampus. This recording from dorsal CA1 was made 0.7 $\mathrm{mm}$ posterior, $0.7 \mathrm{~mm}$ lateral, and $0.3 \mathrm{~mm}$ dorsal to the injection site. The recording from the ventral hippocampus was made $2 \mathrm{~mm}$ posterior, $2.5 \mathrm{~mm}$ lateral, and $3.4 \mathrm{~mm}$ ventral to the injection site. The threshold for recording an event was set to $39 \mu \mathrm{V}$ on all tetrode channels. Tetrode energy measures the instantaneous activity detected by a tetrode. It was defined as the sum of the areas under the four tetrode waveforms. The tetrode energy is plotted for each event as a function of time relative to TTX Injection. Vertical line 1 indicates insertion of the injection needle. Lines 2 and 3 indicate the start and end of the TTX infusion. Line 4 indicates when the dorsal electrode was moved $(10 \mu \mathrm{m})$ to mechanically stimulate the hippocampus. The robust response to mechanical stimulation indicates that although spontaneous discharge in the dorsal hippocampus was limited $7 \mathrm{~h}$ after TTX injection, action potentials could be evoked. The local field potentials (LFP) recorded at the dorsal $(\boldsymbol{B})$ and ventral $(\boldsymbol{C})$ sites are presented in spectrograms. TTX immediately attenuated LFPs at most frequencies in the dorsal site; gamma frequencies took $\sim 1 \mathrm{~h}$ to reach the reduced steady state level. In the ventral site, except immediately after injection, TTX did not attenuate LFPs. In fact, starting at $\sim 40$ min after injection power increased in the beta $(10-25 \mathrm{~Hz})$ band. 
A
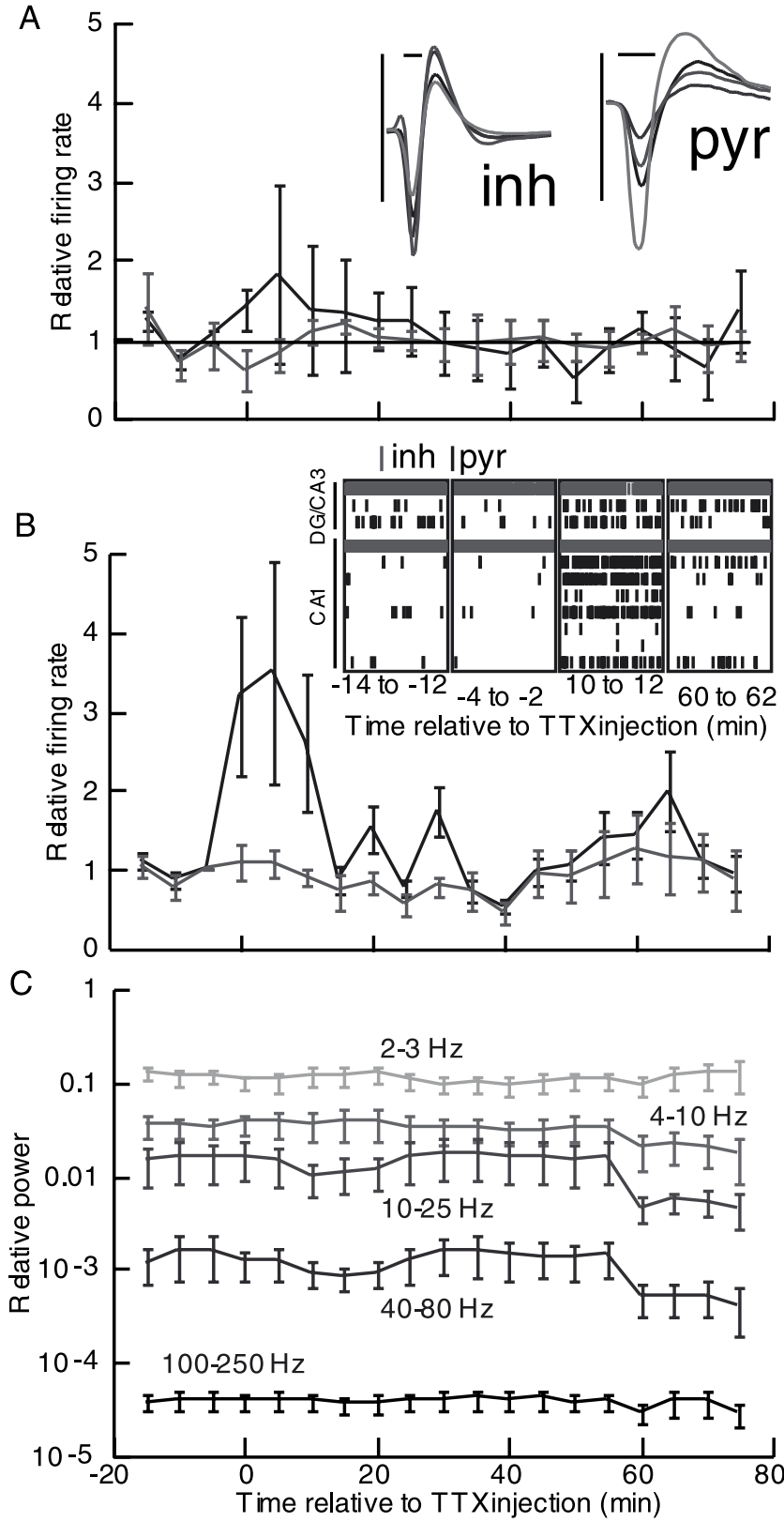

Figure 3. Effects of unilateral saline and TTX injection on the uninjected hippocampus. $\boldsymbol{A}$, Average $2 \mathrm{~ms}$ tetrode waveforms from an interneuron and pyramidal cell illustrate a characteristic difference in the durations of the sodium spike (inset). Calibration: interneuron (inh), 125 $\mu \mathrm{V}, 325 \mu \mathrm{s}$; pyramidal cell (pyr), $125 \mu \mathrm{V}, 552 \mu \mathrm{s}$; indicate duration on the largest waveform. Firing rates of units that were active from -5 to 0 min were normalized by the rate in that interval. Saline injection did not alter firing rates. $\boldsymbol{B}$, Raster representation of simultaneously recorded cells during four $2 \mathrm{~min}$ episodes (inset). The injection did not change the firing of presumptive interneurons (gray), but presumptive pyramidal cells (black) dramatically and transiently increased their discharge. Presumptive pyramidal cells increased their discharge almost immediately for $\sim 15 \mathrm{~min}$ ( $p<0.05$, relative to $-5 \mathrm{~min}$ ). Presumptive interneurons did not change their rates. $C$, The relative power in the delta, theta, beta, gamma, and ripple frequency bands did not change during the recordings. Error bars indicate SE.

after $15 \min \left(F_{(18,1197)}=2.82 ; p=7.4 \times 10^{-5}\right)$ (Fig. $\left.3 B\right)$. Interneurons recorded on the same electrodes as pyramidal cells did not change their rates systematically. The changes in rate were independent of the simultaneously recorded LFP because power in the delta, theta, beta, gamma, and ripple frequency bands did not change significantly during the recordings (Fig. $3 C$ ).

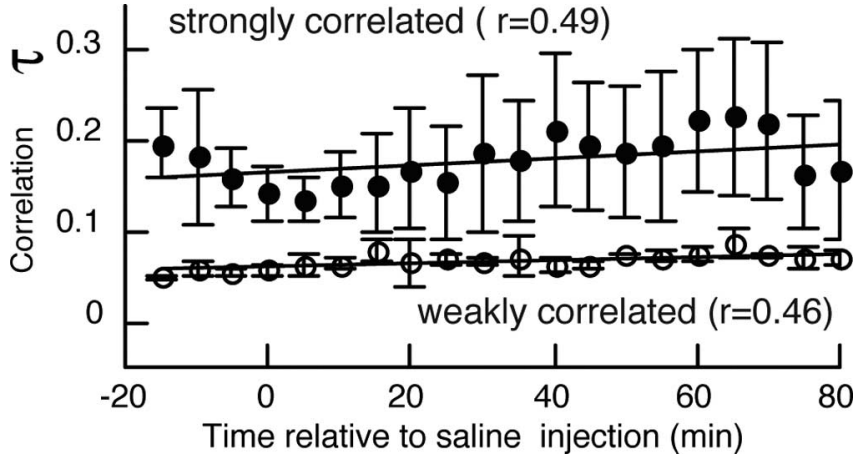

Figure 4. Saline injection did not change coactivity in the uninjected hippocampus. Coactivity was measured by the Kendall correlation $\tau$ of spike counts in $250 \mathrm{~ms}$ bins between 52 pairs of presumed pyramidal cells recorded from four rats. Pairs with preinjection correlations below and above the median correlation were classified as weakly and strongly correlated, respectively. Error bars indicate SE.

\section{Coactivity in the uninjected hippocampus}

The TTX-induced activation of pyramidal cells in the uninjected hippocampus could have increased chances for pyramidal cells to discharge together. That could lead to a general increase of the connections among pyramidal cells because of activitydependent plasticity mechanisms (O’Dell and Kandel, 1994). This predicts that weak connections would strengthen more than already strong connections.

The central hypothesis of this study is that TTX injection impairs subgrouping by causing cognitive disorganization. The basis of the idea is the theory that cognitive coordination is manifest as synchronized coupling among neurons within a cell assembly and uncoupled discharge of neurons from different assemblies (von der Malsburg, 1981). This reasoning predicts that to selectively impair subgrouping of representations while the representations themselves are preserved, cell pairs that fired independently before TTX injection should coactivate after the injection. The coactivity of simultaneously recorded pairs of cells is typically used to estimate the functional coupling of extracellularly recorded cells (Wilson and McNaughton, 1994; Rieke et al., 1997; Sutherland and McNaughton, 2000), so Kendall's correlation between spike counts was calculated. Cell pairs with correlations below and above the median during the 15 min before TTX injection were taken to represent the initially "weak" and "strong" correlations, respectively. Correlations among the group of weakly correlated cell pairs tended to be $\leq 0.05$, a level indicating independent coupling of these cells.

Saline injection did not change either the initially weakly or strongly correlated cell pairs (Fig. 4) but TTX injection induced changes in accord with the hypothesis (Fig. 5). The initially weak correlations calculated at $250 \mathrm{~ms}$ resolution became stronger and more variable $\sim 40 \mathrm{~min}$ after TTX injection $\left(F_{(18,985)}=6.10\right.$; $p<$ $3 \times 10^{-14}$ ) (Fig. $5 A, B$ ). Dunnett's test indicated that the postTTX correlations were significantly greater than the pre-TTX correlations immediately after and from $40 \mathrm{~min}$ and onwards, except for the $45 \mathrm{~min}$ time point. In contrast, the initially strong correlations decreased in correspondence with the increased pyramidal firing. They then became more variable $\left(F_{(18,1203)}=2.36\right.$; $p=0.001$ ) (Fig. $5 A, B$ ). Dunnett's test between the initially strongly correlated pairs indicated the correlations were lower only 5-20 min after TTX was injected. The increase of the initially weak correlations was modest because they only reached $57 \%$ of the initially strong correlations before injection. When all cell pair correlations were analyzed together, the trend for correla- 
A initially weakly correlated

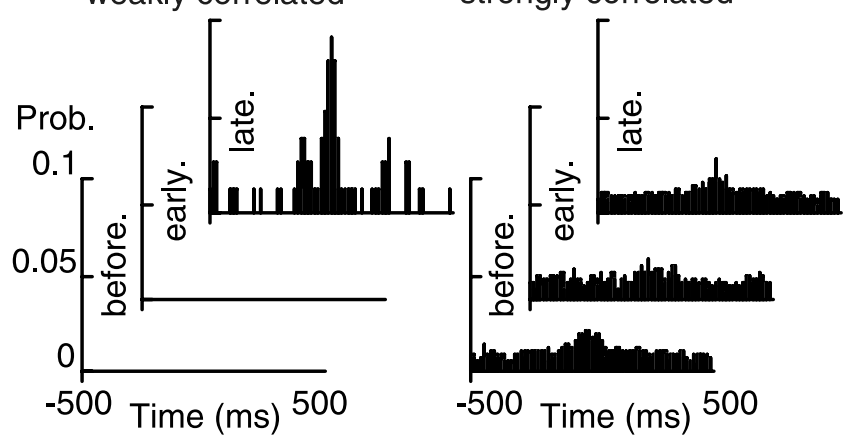

B 0.2 strongly correlated $(r=0.12)$

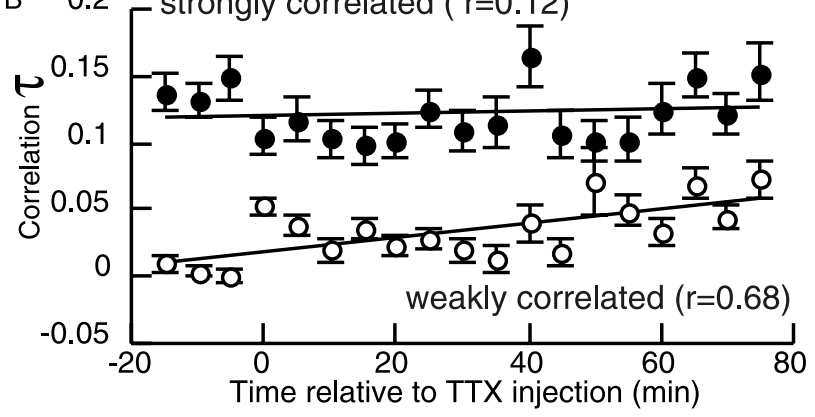

C
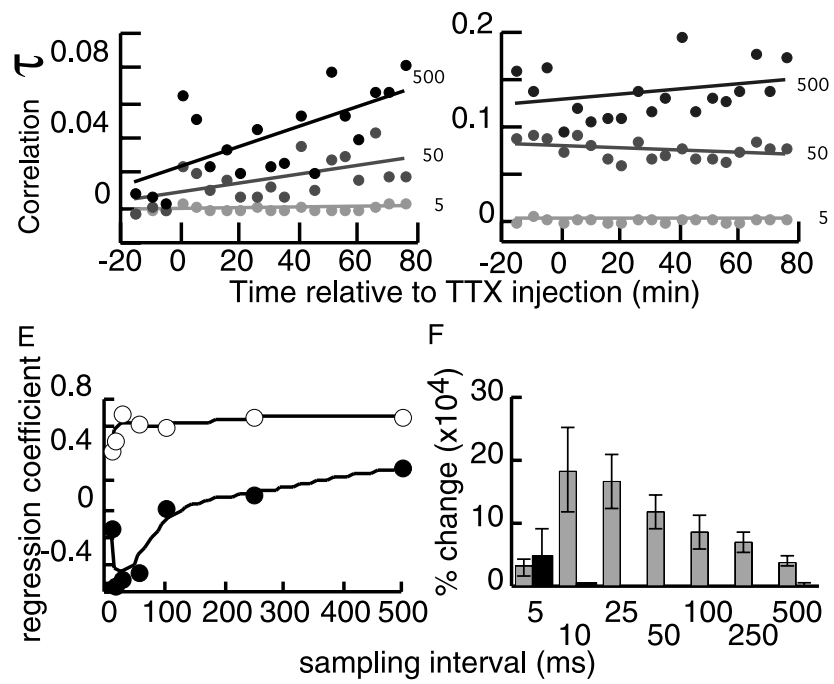

Figure 5. The TTX injection changed correlated discharge in the uninjected hippocampus.A, Cross-correlograms that clearly illustrate the changes that were typical for weakly and strongly correlated cell pairs are given for the $15 \mathrm{~min}$ before, immediately after (early), and from 60 to 80 min (late) after TTX injection. Correlations for these histograms were calculated at $250 \mathrm{~ms}$ resolution. Before injection, the correlation of strongly correlated pairs was quantified by $\tau=0.18$. Immediately after injection, it decreased $(\tau=0.08)$ and then later it recovered $(\tau=0.24)$. The weakly correlated pair was uncorrelated before $(\tau=-0.004)$ and early after $(\tau=-0.009)$ injection, but $1 \mathrm{~h}$ later it had substantially increased $(\tau=0.15)$. $\boldsymbol{B}$, The Kendall correlation $\tau$ of spike counts in $250 \mathrm{~ms}$ bins between pairs of presumed pyramidal cells. Pairs with pre-TTX correlations below and above the median correlation were classified as weakly and strongly correlated, respectively. TTX increased the correlation in the weakly correlated pairs immediately after the injection and from $\sim 40 \mathrm{~min}$ and onwards. The correlations of the initially strongly correlated pairs decreased transiently when pyramidal firing rates were increased. Linear regression lines and the regression coefficients are given. $\boldsymbol{C}, \boldsymbol{D}$, Timescale analyses of the changes in correlated discharge between presumed pyramidal cells in the uninjected hippocampus. The correlated discharge of the weakly $(\boldsymbol{C})$ and strongly $(\boldsymbol{D})$ correlated pairs of cells was characterized every $5 \mathrm{~min}$ for different sampling intervals from 5 to $500 \mathrm{~ms}$ (only 5, 50,500 ms intervals shown). The change in the correlations as a function of the time relative to TTX injection is represented by the regression line for each sampling interval. The weakly correlated pairs had positively sloped regression lines, whereas the strongly correlated tions to increase was also significant $\left(F_{(18,2207)}=2.64 ; p=\right.$ 0.0002 ), indicating that regression to the mean does not account for the increase in the initially weakly correlated cell pairs.

The correlations between the discharge of pyramidal cells and interneurons were also examined (Fig. 6). The initially weakly correlated pairs did not change $\left(F_{(18,582)}=1.35 ; p=0.15\right)$ but the initially strongly correlated pairs decreased coactivity during the time corresponding to increased pyramidal cell firing $\left(F_{(18,727)}=\right.$ 5.11; $\left.p=4 \times 10^{-11}\right)$. However, the only significant differences from the correlations before TTX were at 40 and $65 \mathrm{~min}$ when the values were increased.

\section{Timescale of the TTX-induced coactivity}

If the TTX-induced coactivity is related to gamma-based binding (Singer, 1999), then the coactivity should manifest at the timescale of gamma. Furthermore, if the TTX-induced coactivity is related to the cognitive disorganization associated with disorganization in schizophrenia, one also expects the coactivity to manifest at the timescale of gamma because altered gamma is associated with schizophrenia (Kwon et al., 1999; Spencer et al., 2003) and correlates with disorganization symptoms (Spencer et al., 2004; Tekell et al., 2005).

The timescale of the TTX-induced coactivity was estimated from the correlations at different sampling intervals. Because estimates of the correlation at individual time points are likely to be more inaccurate than estimates from many measurements, the average correlations for different time intervals were fitted to a linear function of time and the functions were compared. The regression of the initially weak correlations was significant and positive for all sampling intervals (Fig. 5C). In contrast, the regressions of the initially strong correlations were only significant at short sampling intervals $(10,25,50 \mathrm{~ms})$ when they were negative (Fig. 5D).

If increased correlations were caused by coactivation at a particular temporal resolution, then the regression should be weak at sampling intervals lower than the critical interval. The regression should suddenly increase for sampling intervals at the critical resolution and the increased regression would be maintained at longer sampling intervals. The pattern of the initially weakly correlated pairs of pyramidal cells resembled this expectation (Fig. 5E).

Place avoidance experiments demonstrated the TTX injection impaired subgrouping when behavior was tested between 60 and 80 min (Cimadevilla et al., 2001; Wesierska et al., 2005). For each sampling interval, the relative change in the average correlation for each cell pair was calculated as the difference in the correlation during 60-80 min after TTX injection relative to the correlation before the injection. For statistical comparisons of these changes for different sampling intervals, this difference was normalized by the pre-TTX correlation of the cell pair because the magnitude of the correlations increased with longer sampling intervals (Fig. 5). In initially weakly

$\leftarrow$

pairs had negative or flat regression lines. $\boldsymbol{E}$, The regression coefficients from $\boldsymbol{C}$ and $\boldsymbol{D}$ plotted as a function of the sampling interval. Weakly correlated pairs (open circles) had increased regression coefficients at $25 \mathrm{~ms}$ and longer, whereas it was reduced in the strongly correlated pairs (filled circles) at $10-50 \mathrm{~ms}$. $\boldsymbol{F}$, The relative change of the correlation averaged from 60 to $80 \mathrm{~min}$ after TTX injection, relative to the correlation averaged from 15 to 0 min before TTX injection plotted as a function of sampling interval. The weakly correlated pairs were generally increased severalfold and the strongly correlated pairs were not increased. The increase in the correlations at $10-50 \mathrm{~ms}$ sampling intervals were greater than at the $5 \mathrm{~ms}$ interval (Dunnett's one-tail tests), suggesting that the increase of correlated discharge was predominantly at the timescale of gamma. Error bars indicate SE. 
A

$$
\begin{aligned}
& \text { initially } \\
& \text { weakly correlated }
\end{aligned}
$$
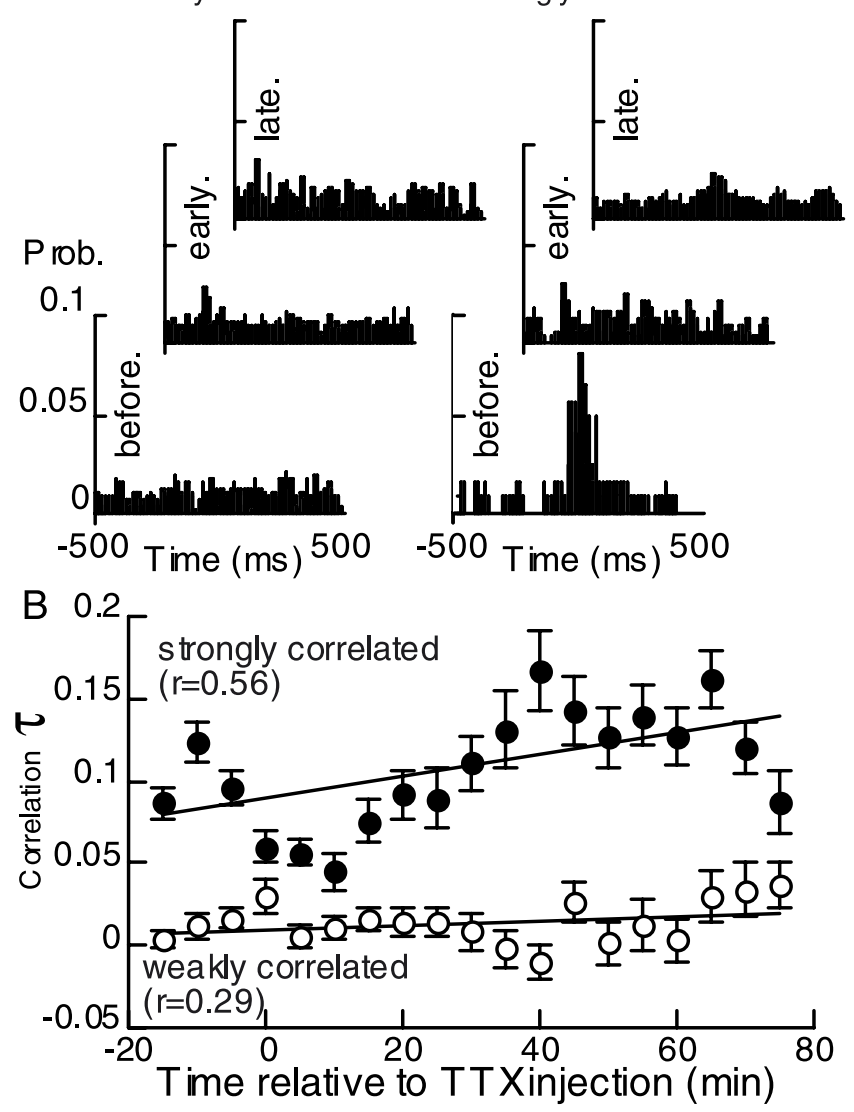

C

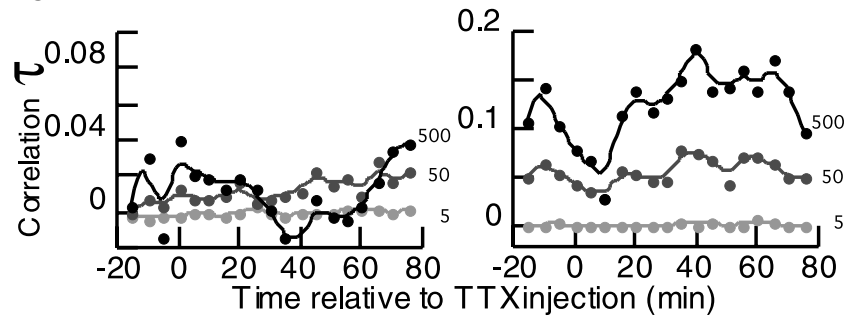

Figure 6. The correlations between presumed pyramidal cells and interneurons decreased transiently for the initially strongly correlated pairs. The pattern of change corresponded to the changes between the initially strongly connected pairs of pyramidal cells (Fig. 5). The correlations between the initially weakly correlated pairs did not change. $A$, Cross-correlograms that clearly illustrate the changes that were typical for weakly and strongly correlated cell pairs are given for the $15 \mathrm{~min}$ before, immediately after (early), and from 60 to $80 \mathrm{~min}$ (late) after TTX injection. The correlation of the strongly correlated pair before injection $(\tau=0.12)$ decreased immediately after injection $(\tau=0.02)$, and 60 min later it was restored $(\tau=0.10)$. The weakly correlated pair $(\tau=0.01)$ was about the same early $(\tau=0.01)$ and late $(\tau=0.009)$ after injection. $\boldsymbol{B}$, The Kendall correlation $\tau$ of spike counts in $250 \mathrm{~ms}$ bins between pairs of presumed pyramidal and inhibitory cells. Pairs with pre-TTX correlations below and above the median correlation were classified as weakly and strongly correlated, respectively. TTX did not change the correlation in the weakly correlated pairs. The correlations of the initially strongly correlated pairs decreased transiently when pyramidal firing rates were increased. Linear regression lines and the regression coefficients are given. $C, D$, Timescale analyses of the changes in correlated discharge between presumed pyramidal cells and interneurons in the uninjected hippocampus. The correlated discharge of the weakly $(\boldsymbol{C})$ and strongly $(\boldsymbol{D})$ correlated pairs of cells were characterized every $5 \mathrm{~min}$ for different sampling intervals from 5 to $500 \mathrm{~ms}$ (only 5, 50,500 ms shown). The time courses of the changes are highlighted by a smooth fit of the data for each sampling interval. The weakly correlated pairs had no tendency to change but at intervals of 100 ms or greater, the strongly correlated pairs decreased for $\sim 15$ min after TTX injection. Error bars indicate SE. correlated cell pairs, the relative increase in correlations was severalfold at sampling intervals $>5 \mathrm{~ms}\left(F_{(6,425)}=2.85 ; p<0.01\right)$ (Fig. $\left.5 F\right)$. The largest changes of correlation were for the sampling intervals corresponding to gamma periods $(10-50 \mathrm{~ms})$. In contrast, the initially strong correlations were unchanged $\left(F_{(6,528)}=1.43 ; p>0.2\right)$.

When all cell pairs were considered together, there was a strong inverse relationship between the pre-TTX $(-15-0 \mathrm{~min})$ correlation of a cell pair and the change of this correlation $60-80$ min after the injection. This is because cell pairs with initially weak correlations changed their correlations, whereas pairs with initially strong correlations did not change. This inverse relationship was observed for all sampling intervals (range of Pearson's coefficients, -0.52 to $-0.62 ; p<0.01$ ). This was the basis of the rule (Eq. $5 \mathrm{~b}$ ) for corrupting weights in the network simulations that were used to model the effects of the TTX injection in the next section.

The correlations between presumed pyramidal cells and interneurons were also calculated at different temporal resolutions. TTX did not induce monotonic changes so the regression and time-scale analyses were not performed. The initially weak correlations were relatively stable and did not reach a level different from chance (Fig. 6B). The decrease of the initially strong correlations immediately after the TTX injection was only observed for time intervals of $100 \mathrm{~ms}$ and greater (Fig. 6D). The $100 \mathrm{~ms}$ timescale matches the course of $\mathrm{GABA}_{\mathrm{B}}$-mediated inhibition in the hippocampus of the urethane-anesthetized rat (Molyneaux and Hasselmo, 2002).

How increased coactivity can cause symptoms of disorganization

Why should increased coactivity amongst principal cells impair subgrouping and contextual modulation but spare representational memory and navigation? Coactivity may occur by increasing the common input to cell pairs. Alternatively, increased synaptic connections between cell pairs may also induce coactivity. Regardless of the mechanism, the increased correlation of discharge indicates that the functional coupling between cells increased, and this can be modeled by manipulating the connection weights in a Hopfield-type artificial neural network in which firing rates rather than spike times are simulated.

A previously described Hopfield-type hippocampal network model (Rolls et al., 2002) was adapted to model subgrouping of stationary positions in the room and rotating positions in the arena. The model had two sets of competing attractor states corresponding to a representation of positions in the room and an independent representation of positions in the arena. Before any input, the network activity was homogeneous and low (Fig. 7, $t=$ $0 \mathrm{~s}$ ). Momentary input corresponding to, for example, a location determined by room cues, induced an attractor state characterized by selective activation of the "room place cells" (the cells with localized firing defined with respect to room cues). This characteristic pattern of activation (the "activity packet") (McNaughton et al., 1996; Samsonovich and McNaughton, 1997; Tsodyks, 1999) persisted in the absence of input, in accord with the definition of an attractor that activity converges to a steady and stable state in constant conditions (Fig. 7). Short (up to $25 \mathrm{~ms}$ ) inputs corresponding to different locations within one frame (e.g., the room frame) quickly activated corresponding spatial representations (Fig. 7A1). Subsequent input corresponding to a position in the rotating arena caused the representation of the current room position to be replaced by the representation of the current arena position (Fig. 7B1), which was characterized by the selective activation of "arena place cells." Inputs corresponding to both 
room and arena positions caused the network to converge to represent only the stronger of the inputs (Fig. 7C1). The activation of either the representation of a room or arena position (but not both) demonstrates subgrouping and mimics normal place avoidance behavior in that, moment to moment, the rat and network determine the current position in either the room or the arena, without confusing positions from the two frames.

We considered two models of increasing connection weights to explain the impairment in subgrouping associated with TTXinduced coactivity. The first model was based on the observation that the TTX injection caused a general increase of coactivity. It was assumed that all cell pairs could have been coactivated to an equal extent and with equal probability. A "general" corruption rule (Eq. 5a) was implemented to model this. Each connection weight was increased by a random number from the interval $(0, p)$ : $w_{i j}^{(1)}=w_{i j}+p \times \eta$; the maximum weight was limited to 1 . First, the simulations were performed for the nonsymmetric network. For $p \leq 0.15$, as long as inputs were not dissociated, meaning as long as they were from positions within a single reference frame, for example the room, the network activity represented those positions as faithfully as the uncorrupted network (Fig. 7A2). When $p=$ 0.16 , the network failed to represent a location within any frame; it converged to a parasitic attractor (data not shown). As in the study by Hoffman (1987), we define a parasitic attractor as an attractor in which the network activity does not represent network inputs faithfully because the basin of attraction of such an attractor is so large that the system converges to the parasitic attractor state with high probability for many different inputs.

The second model was based on the observation of an inverse relationship between coactivity before the TTX injection and the change in coactivity caused by the injection. That observation suggested the main consequence of the TTX injection was to cause independent networks of neurons to fire together. That observation was implemented as a "selective" corruption rule (Eq. 5b). Accordingly, large weights were affected less than small weights. Because large weights in the model encoded the representation of positions within a frame, we expected that the network with weights corrupted according to Eq. $5 \mathrm{~b}$ would be able to switch between location representations within one frame for values of $p>0.15$. Indeed, as long as the inputs were already subgrouped to be from positions within either the room or the arena (compare Fig. 7A1, A2), the network faithfully represented locations within a frame for $p \leq 0.21$. When the connectivity was randomly increased between 0 and $>21 \%$ of the difference of the connection from the maximum value 1 (Eq. $5 b)(p \leq 0.21)$, the room input, while it was present, induced both a representation of the corresponding room position and some arena location that did not fade as in the case of $p=0.2$ (Fig. 7A2), but remained stable (data not shown). The strengthened connectivity had its most dramatic effect on responses to dissociated room and arena
Uncorrupted network

Corrupted network

.2s $0.3 \mathrm{~s} \quad 0.5 \mathrm{~s} \quad 1.0 \mathrm{~s} \quad 2.0 \mathrm{~s} 16.0 \mathrm{~s}$ s $0.3 \mathrm{~s} \quad 0.5 \mathrm{~s} \quad 1.0 \mathrm{~s} \quad 2.0 \mathrm{~s} \quad 16.0 \mathrm{~s}$

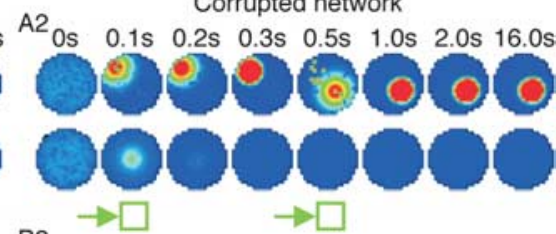
B2

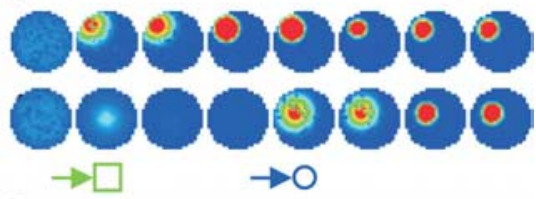
$\mathrm{C} 2$

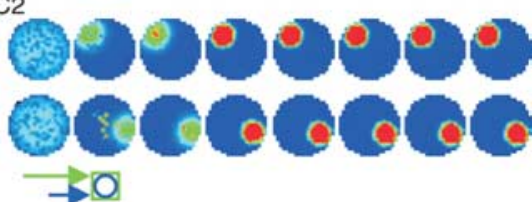

Figure 7. Network simulations illustrate that randomly increasing excitatory- excitatory connections impaired subgrouping represtations of room and arena locations. Location-specific ensemble activity is represented as an activity packet. Each

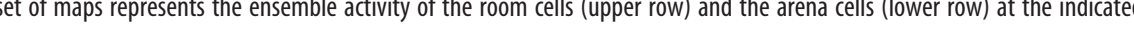

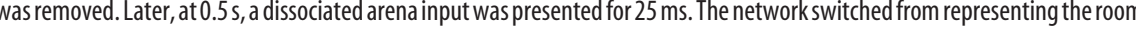
activity persisted after the arena input was presented so both the room and sented for $25 \mathrm{~ms}$. When the inputs ceased (C1), only the stronger room input was persistently represented ( $\mathbf{C}$ ) but both locations were simultaneously and persistently represented in the network with increased connectivity.

inputs. Figure 7B2 represents the typical behavior of the selectively corrupted network with $0-20 \%$ increased weights. When room input was followed by arena input, the network converged to a pathological state with simultaneously active room and arena cells. When both the room and arena inputs were simultaneous, like the uncorrupted network, the network with $0-20 \%$ increased weights converged to represent only the stronger of the inputs. When the network weights were corrupted by $0-25 \%$, the network persistently represented both room and arena locations in response to simultaneous room and arena inputs (Fig. 7C2). Appropriate network behavior was restored by increasing inhibition $9 \%$ (changing $w^{\mathrm{INH}}$ from 0.32 to 0.35 ), predicting that mild doses of a GABA agonist like a benzodiazepine might attenuate the TTX-induced impairment of cognitive coordination.

\section{The importance of corrupting initially weak connection weights}

Because the coupling between independent representations should be low, we considered the possibility that the subgrouping impairment was caused by the increased coupling of cells that coded independent representations. We used the network model to evaluate this idea because, unlike the hippocampus, in the model we could be certain that room-arena connections were between cells that code independent representations and that room-room and arena-arena connections were between cells that code the same representation. We then selectively corrupted either only the between-representation connections or the 
Table 1. Simulation results suggest that corrupting connection weights between room and arena cells is necessary and sufficient to induce selective subgrouping failures

\begin{tabular}{lllll}
\hline $\begin{array}{l}\text { Corruption rule } \\
\begin{array}{l}\text { General: Eq. 5a } \\
\text { Selective: Eq. 5b }\end{array}\end{array}$ & $\begin{array}{l}\text { Maximal } \\
\text { tolerated } \\
\text { corruption }\end{array}$ & $\begin{array}{l}\text { Critical } p \text { for } \\
\text { representation } \\
\text { failures }\end{array}$ & $\begin{array}{l}\text { Critical } p \text { for } \\
\text { subgrouping } \\
\text { failures }\end{array}$ \\
\hline General & Room-arena & $p=0.21$ & $p \geq 0.21$ & $p \geq 0.13$ \\
Selective & Room-arena & $p=0.24$ & $p \geq 0.24$ & $p \geq 0.15$ \\
General & Room-room and arena-arena & $p=0.22$ & No failures for $p \leq 0.22$ & No failures for $p \leq 0.22$ \\
Selective & Room-room and arena-arena & $p=0.32$ & No failures for $p \leq 0.32$ & No failures for $p \leq 0.32$ \\
\hline
\end{tabular}

within-representation connections and observed the effects on the ability of the network to switch from one representation to another ("subgroup") and to switch from representing one location to another in the same reference frame ("represent"). We used networks with symmetric connection weights to minimize the dependence of the results of these experiments on the inhomogeneity of the weights. The results are summarized in Table 1. The results were qualitatively the same after corrupting the network according to the general (Eq. 5a) or selective (Eq. 5b) corruption rules. We thus only report the results of the selective rule now and give the results from both rules in Table 1. In general, not surprisingly, the network could tolerate more corruption according to the selective rule than the general rule. Beyond a certain magnitude of corruption, in the absence of input, the network would spontaneously represent a location near the center of the space. We used these $p$ values as the upper limit for corrupting the network in the experiments that follow.

To test whether it was sufficient to corrupt the weights between room and arena cells to induce failures in subgrouping, the network was corrupted and then the weights between the pairs of room cells and between the pairs of arena cells were restored to the originally tuned values. Thus, only the weights for pairs consisting of a room and an arena cell were left corrupted. These room-arena weights account for $50 \%$ of the network connections $(53.2 \%$ of all of the connections with weights $\leq 0.25)$. This was sufficient to induce subgrouping failures when the magnitude of weight corruption was 0.15 or greater. It was not until the corruption was 0.24 or more that the network failed to switch from representing one location to another within one reference frame. Thus, to selectively induce a subgrouping failure, it was sufficient to increase only the weights between room and arena cells.

We then tested whether to induce subgrouping failures it was necessary to increase the coupling between the room and arena cells. After corrupting the connection weights, the weights between the pairs consisting of a room and an arena cell were restored to their initial (weak) values. There were no subgrouping or representation failures for magnitudes of corruption that were less than the level at which the network ceased to be stable before input. In summary, to induce a selective subgrouping deficit in the model, it was both necessary and sufficient to increase the connection weights between the initially weakly connected cells that encoded independent network representations.

We stress that both Equations $5 \mathrm{a}$ and $5 \mathrm{~b}$ produced qualitatively similar results. This is because the important corrupting change was to the weakly connected cells, and both equations produced similar increases in these weights. The equations differed in how they affected the strongly connected cells, but increasing these weights did not selectively produce subgrouping failures.

\section{Discussion}

The TTX injection suppressed discharge in the injected hippocampus and altered discharge in the uninjected hippocampus.
The first main finding is that the TTX injection coactivated pyramidal cell pairs that initially discharged independently. In accord with temporal binding proposals and the definition of cognitive disorganization, altered firing rates did not accompany the coactivation. This result supports the hypothesis that impaired hippocampal cognitive coordination caused the TTXinduced impairment of subgrouping distal and local stimuli for place avoidance behavior (Wesierska et al., 2005). The second main finding is that the TTX-induced coactivity occurred at the timescale of gamma. This coactivity may represent failed segregation of cell assemblies (Singer, 1999) and an index of the disorganization in schizophrenia (Spencer et al., 2003). TTX-induced coactivity, therefore, has predictive validity as a model of the disorganization in schizophrenia. A second prediction, that the TTX-induced cognitive disorganization should selectively impair behavior requiring subgrouping of relevant and irrelevant stimuli, was already confirmed (Wesierska et al., 2005). Although at face value schizophrenia-associated neurobiology, such as hippocampal inhibitory interneuron dysfunction (Benes, 2000), disinhibition induced by psychotomimetics (Fenton, 2005; Jodo et al., 2005), hippocampal hyperactivity related to positive symptoms (Liddle et al., 1992; Busatto et al., 1997; Heckers, 2001; Heckers and Konradi, 2002), and altered functional relationships in schizophrenia (Benes, 1999) seem related to the TTX experimental model, we will not speculate on their relevance until these features are examined experimentally.

\section{Effect of injecting TTX into one hippocampus}

Enough TTX to block neural activity should have diffused isotropically (Hrabetova, 2005) $\sim 1 \mathrm{~mm}$ in $25 \mathrm{~min}$. The TTX concentration would have been subeffective within that volume by $200-$ 300 min (Zhuravin and Bures, 1991). The TTX blocked neural activity at a $1 \mathrm{~mm}$ distant CA1 site (Fig. 2) within a few minutes, probably because intrahippocampal trisynaptic transmission was blocked at the injection site (Klement et al., 2005). The blockade lasted $4-5 \mathrm{~h}$, as reported for the midbrain (Zhuravin and Bures, 1991) and extended to ventral hippocampal regions $>4.5 \mathrm{~mm}$ away. TTX injections of a twice-greater concentration were not effective beyond $1.5 \mathrm{~mm}$ (Harlan et al., 1983; Zhuravin and Bures, 1991), suggesting the activity block of the ventral hippocampus was partly caused by blocking the fimbria fibers within $1.5 \mathrm{~mm}$ of the injection. Ventral hippocampal LFPs were mostly preserved (Fig. 2C), indicating that these do not reflect spiking and that in the urethane-anesthetized rat, intact perforant path and amygdala inputs (Petrovich et al., 2001) were not sufficient to drive action potential discharge that was blocked 30-200 min after TTX injection. Because altered gamma (increased beta) in EEG is associated with disorganization (Spencer et al., 2004), it will be important to determine whether the TTX-induced beta LFP oscillations in ventral hippocampus (Fig. 2C) index behavioral disorganization in rats.

The activity block of the injected hippocampus reduced commissural excitation of the uninjected hippocampus, which should have decreased feedforward inhibition there (Buzsaki and Czeh, 1981; Buzsaki, 1984; Tomasulo and Ramirez, 1993). Indeed, in contrast to the persistent $(>4 \mathrm{~h}$ ) activity blockade in the injected hippocampus, firing rates changed transiently in the uninjected dorsal hippocampus. Presumed principal cells but not neighboring interneurons increased firing for $15 \mathrm{~min}$ (Fig. 3). 
Although increased pyramidal discharge is consistent with disinhibition, this was not reflected in unchanged interneuron rates in this or other studies of psychotomimetically induced disinhibition (Jodo et al., 2005). Perhaps interneuron rates decreased in other layers, but the lack of change is more likely because the major excitatory input to interneurons after the injection was from the activated pyramidal cells. This pyramidal-interneuron feedback contributes to the strong homeostasis of hippocampal firing rates (Buzsaki et al., 2002). The transient increase in pyramidal cell firing is consistent with firing rate homeostasis mediated by coupled excitation and inhibition. Initially coactive pyramidal and interneuronal cell pairs decreased their coactivity but only while pyramidal discharge rates were increased, suggesting the feedback had initially uncoupled and was then restored. Population rate constancy is a feature of attractor neural networks within which a balance between recurrent excitation and feedback inhibition operates to maintain network output in the presence of partial input (van Vreeswijk and Sompolinsky, 1998; Shu et al., 2003).

\section{TTX-induced cognitive disorganization}

Cognitive coordination is the set of processes that control spike times among neurons without affecting individual discharge properties like firing rates. One hour after TTX injection, spike timing between cells in the uninjected hippocampus was altered but firing rates were not. The TTX-induced coactivation of initially uncoupled pyramidal cell pairs was detected from $\sim 40 \mathrm{~min}$ after TTX injection (Fig. 5). This is unlikely to reflect a process of regression-to-the-mean because (1) the increase was observed when all cell pairs were analyzed together, (2) the increase of the initially weakly correlated cell pairs was delayed, (3) it was not accompanied by decreased correlations among initially highly correlated cell pairs, and (4) the pattern of correlation changes was not observed among pyramid-interneuron pairs.

Schizophrenic subjects, impaired in a gestalt task requiring perceptual grouping of visual stimuli, had reduced gamma and increased beta power in visual stimulus-evoked oscillations in the parietal and occipital EEG (Spencer et al., 2004). These data add to the growing consensus that disturbed neural coordination at gamma (and beta) frequencies may underlie disorganized processing in different sensory modalities (Kwon et al., 1999; Spencer et al., 2003) during sleep and rest (Tekell et al., 2005). This predicts that the TTX-altered coactivity would occur at gamma frequencies if it reflects a schizophrenia-related phenomenon. Consistent with this idea, the TTX-induced coactivity between pyramidal cells emerged and was maximal at gamma periods (Fig. $5 E, F$ ).

Whereas the initially uncoupled cell pairs increased 10-50 ms coactivity, the initially strongly correlated pairs significantly and specifically decreased 25-50 ms coactivity (Fig. 5). Although there was a consistent tendency for reduced gamma in the hippocampal LFP at the time of the behavioral impairment (60-80 min postinjection), the trend was not significant. Whereas increased beta oscillations were not observed in dorsal hippocampal LFPs (Fig. 3), they were observed in the ventral hippocampus (Fig. 2C), which has direct connections to the prefrontal circuits thought to be affected in schizophrenia. Assuming that gamma synchrony is important for hippocampal information processing (McBain and Fisahn, 2001; Harris et al., 2003), the selective disorganization of this coactivity in the uninjected hippocampus may underlie the TTX-induced behavioral impairment of subgrouping (Wesierska et al., 2005).

Increased coactivity in the uninjected hippocampus was inde- pendent of firing rate changes and specific to the discharge of the presumed pyramidal cell pairs that initially fired independently. The specificity of the altered correlations precludes explanations for the increases based on the duration of anesthesia, altered rates, or boundary effects. The pyramidal cell coactivity was the TTX-induced change in the uninjected hippocampus that persisted at the time of the behavioral impairment of place avoidance requiring subgrouping (Cimadevilla et al., 2001; Wesierska et al., 2005). Because these alterations were observed under anesthesia, they cannot be consequences of TTX-induced perceptual, sensorimotor, or behavioral alterations. An important next step is to record the effects of the TTX injection in behaving animals. There are strong positive and negative firing covariations in place cell pairs with overlapping firing fields (Harris et al., 2003) (A. A. Fenton and E. Kelemen, unpublished observations), and the cognitive disorganization hypothesis predicts selective alterations of the covariance. Nonetheless, the urethane-anesthetized preparation provides a means for a high throughput neurophysiological assay that may be valuable for drug discovery.

\section{How TTX-induced coactivity can cause disorganization symptoms}

The modeling explains that increased coactivation of weakly coupled principal cells can selectively produce disorganization. Additional studies are required to determine whether TTX-induced disinhibition or indiscriminate synaptic potentiation caused the coactivity. Regardless of the cause, the result was increased functional coupling. A severe general increase of coupling in the model (Eq. 5a) impaired activation of the stored representations, analogous to the impaired retrieval of spatial memory caused by globally saturating long-term potentiation at hippocampal synapses (Brun et al., 2001). However, the disturbing effect was only because the connection between initially weakly coupled cells had increased. It is an important general result that increasing the coupling of the initially weakly coupled elements in the model, specifically those between cells coding independent representations, was necessary and sufficient to impair segregated activation of stored representations without altering retrieval of the representations themselves (Fig. 7, Table 1). Dissociating inputs to the corrupted network caused it to respond inappropriately, as if there was stimulation from both reference frames. This defines a parasitic attractor, a pathological steady and stable state of activity that does not reflect reality and is used to model hallucinations (Hoffman, 1987).

These data suggest a model for cognitive disorganization in which hippocampal patterns of response fail to segregate in accord with what is relevant and irrelevant. However, cognitive disorganization would arise not merely because the information content of hippocampal output is inappropriate. Disorganization would manifest because the increased coactivity of hippocampal output will exert altered feedforward inhibitory control of prefrontal (Tierney et al., 2004) and possibly accumbal (Pennartz and Kitai, 1991) circuits. Preliminary 2-deoxyglucoseglucose imaging indicates that the TTX injection induced hypometabolic changes in ventral hippocampal and prefrontal networks (Fenton and D. Dow-Edwards, unpublished observations). This would further disturb the coordination of cognitive representations.

\section{References}

Amit DJ (1989) Modeling brain function: the world of attractor neural networks. Cambridge, UK: Cambridge UP.

Benes FM (1999) Evidence for altered trisynaptic circuitry in schizophrenic hippocampus. Biol Psychiatry 46:589-599. 
Benes FM (2000) Emerging principles of altered neural circuitry in schizophrenia. Brain Res Brain Res Rev 31:251-269.

Brun VH, Ytterbø K, Morris RGM, Moser M-B, Moser EI (2001) Retrograde amnesia for spatial memory induced by NMDA receptor-mediated long-term potentiation. J Neurosci 21:356-362.

Busatto GF, Pilowsky LS, Costa DC, Ell PJ, David AS, Lucey JV, Kerwin RW (1997) Correlation between reduced in vivo benzodiazepine receptor binding and severity of psychotic symptoms in schizophrenia. Am J Psychiatry $154: 56-63$.

Buzsaki G (1984) Feed-forward inhibition in the hippocampal formation. Prog Neurobiol 22:131-153.

Buzsaki G, Czeh G (1981) Commissural and perforant path interactions in the rat hippocampus. Field potentials and unitary activity. Exp Brain Res 43:429-438.

Buzsaki G, Csicsvari J, Dragoi G, Harris K, Henze D, Hirase H (2002) Homeostatic maintenance of neuronal excitability by burst discharges in vivo. Cereb Cortex 12:893-899.

Cimadevilla JM, Wesierska M, Fenton AA, Bures J (2001) Inactivating one hippocampus impairs avoidance of a stable room-defined place during dissociation of arena cues from room cues by rotation of the arena. Proc Natl Acad Sci USA 98:3531-3536.

Engel AK, Fries P, Singer W (2001) Dynamic predictions: oscillations and synchrony in top-down processing. Nat Rev Neurosci 2:704-716.

Fenton AA (2005) Massive increase of hippocampal pyramidal cell firing caused by acute systemic administration of phencyclidine (PCP) to rats. Soc Biol Psychiatry Abstr 676.

Fenton AA, Muller RU (1998) Place cell discharge is extremely variable during individual passes of the rat through the firing field. Proc Natl Acad Sci USA 95:3182-3187.

Fenton AA, Wesierska M, Kaminsky Y, Bures J (1998) Both here and there: simultaneous expression of autonomous spatial memories in rats. Proc Natl Acad Sci USA 95:11493-11498.

Ferbinteanu J, Shapiro ML (2003) Prospective and retrospective memory coding in the hippocampus. Neuron 40:1227-1239.

Gothard KM, Skaggs WE, Moore KM, McNaughton BL (1996a) Binding of hippocampal CA1 neural activity to multiple reference frames in a landmark-based navigation task. J Neurosci 16:823-835.

Gothard KM, Skaggs WE, McNaughton BL (1996b) Dynamics of mismatch correction in the hippocampal ensemble code for space: interaction between path integration and environmental cues. J Neurosci 16:8027-8040.

Harlan RE, Shivers BD, Kow LM, Pfaff DW (1983) Estrogenic maintenance of lordotic responsiveness: requirement for hypothalamic action potentials. Brain Res 268:67-78.

Harris KD, Csicsvari J, Hirase H, Dragoi G, Buzsaki G (2003) Organization of cell assemblies in the hippocampus. Nature 424:552-556.

Hebb DO (1949) The organization of behavior. New York: Wiley.

Heckers S (2001) Neuroimaging studies of the hippocampus in schizophrenia. Hippocampus 11:520-528.

Heckers S, Konradi C (2002) Hippocampal neurons in schizophrenia. J Neural Transm 109:891-905.

Hoffman RE (1987) Computer simulations of neural information processing and the schizophrenia-mania dichotomy. Arch Gen Psychiatry 44:178-188.

Hopfield JJ (1984) Neurons with graded response have collective computational properties like those of two-state neurons. Proc Natl Acad Sci USA 81:3088-3092.

Hrabetova S (2005) Extracellular diffusion is fast and isotropic in the stratum radiatum of hippocampal CA1 region in rat brain slices. Hippocampus 15:441-450.

Jodo E, Suzuki Y, Katayama T, Hoshino K-Y, Takeuchi S, Niwa S-I, Kayama Y (2005) Activation of medial prefrontal cortex by phencyclidine is mediated via a hippocampo-prefrontal pathway. Cereb Cortex 15:663-669.

Klement D, Pastalkova E, Fenton AA (2005) Tetrodotoxin infusions into the dorsal hippocampus block non-locomotor place recognition. Hippocampus 15:460-471.

Kwon JS, O'Donnell BF, Wallenstein GV, Greene RW, Hirayasu Y, Nestor PG, Hasselmo ME, Potts GF, Shenton ME, McCarley RW (1999) Gamma frequency-range abnormalities to auditory stimulation in schizophrenia. Arch Gen Psychiatry 56:1001-1005.

Liddle PF, Friston KJ, Frith CD, Jones T, Hirsch SR, Fackowiack RSJ (1992)
Patterns of cerebral blood flow in schizophrenia. Br J Psychiatry 160:179-186.

McBain CJ, Fisahn A (2001) Interneurons unbound. Nat Rev Neurosci 2:11-23.

McNaughton BL, Barnes CA, Gerrard JL, Gothard K, Jung MW, Knierim JJ, Kudrimoti H, Qin Y, Skaggs WE, Suster M, Weaver KL (1996) Deciphering the hippocampal polyglot: the hippocampus as a path integration system. J Exp Biol 199:173-185.

Molyneaux BJ, Hasselmo ME (2002) $\mathrm{GABA}_{\mathrm{B}}$ presynaptic inhibition has an in vivo time constant sufficiently rapid to allow modulation at theta frequency. J Neurophysiol 87:1196-1205.

O’Dell TJ, Kandel ER (1994) Low-frequency stimulation erases LTP through an NMDA receptor-mediated activation of protein phosphatases. Learn Mem 1:129-139.

O’Keefe J, Recce ML (1993) Phase relationship between hippocampal place units and the EEG theta rhythm. Hippocampus 3:317-330.

Olypher AV, Lansky P, Fenton AA (2002) Properties of the extra-positional signal in hippocampal place cell discharge derived from the overdispersion in location-specific firing. Neuroscience 111:553-566.

Olypher AV, Klement D, Wesierska M, Fenton AA (2003) Inactivating one hippocampus with tetrodotoxin prevents place learning in dissociated reference frames by disturbing the uninjected hippocampus. Sixth IBRO World Congress of Neuroscience. FENS Abstr 1256.

Pennartz CM, Kitai ST (1991) Hippocampal inputs to identified neurons in an in vitro slice preparation of the rat nucleus accumbens: evidence for feed-forward inhibition. J Neurosci 11:2838-2847.

Petrovich GD, Canteras NS, Swanson LW (2001) Combinatorial amygdalar inputs to hippocampal domains and hypothalamic behavior systems. Brain Res Brain Res Rev 38:247-289.

Phillips WA, Silverstein SM (2003) Convergence of biological and psychological perspectives on cognitive coordination in schizophrenia. Behav Brain Sci 26:65-137.

Phillips WA, Singer W (1997) In search of common foundations for cortical computation. Behav Brain Sci 20:657-722.

Press WH, Flannery BP, Teukolsky SA, Vetterling WT (1993) Numerical recipes in $\mathrm{C}$. The art of scientific computing, Ed 2. Cambridge, UK: Cambridge UP.

Ranck Jr JB (1973) Studies on single neurons in dorsal hippocampal formation and septum in unrestrained rats. I. Behavioral correlates and firing repertoires. Exp Neurol 41:461-531.

Rieke F, Warland D, de Ruyter van Steveninck R, Bialek W (1997) Spikes: exploring the neural code. Cambridge, MA: MIT.

Rolls ET, Stringer SM, Trappenberg TP (2002) A unified model of spatial and episodic memory. Proc R Soc Lond B Biol Sci 269:1087-1093.

Rotenberg A, Muller RU (1997) Variable place-cell coupling to a continuously viewed stimulus: evidence that the hippocampus acts as a perceptual system. Philos Trans R Soc Lond B Biol Sci 352:1505-1513.

Samsonovich A, McNaughton BL (1997) Path integration and cognitive mapping in a continuous attractor neural network model. J Neurosci 17:5900-5920.

Shu Y, Hasenstaub A, McCormick DA (2003) Turning on and off recurrent balanced cortical activity. Nature 423:288-293.

Silverstein SM, Kovacs I, Corry R, Valone C (2000) Perceptual organization, the disorganization syndrome, and context processing in chronic schizophrenia. Schizophr Res 43:11-20.

Singer W (1999) Neuronal synchrony: a versatile code for the definition of relations? Neuron 24:49-65.

Spencer KM, Nestor PG, Niznikiewicz MA, Salisbury DF, Shenton ME, McCarley RW (2003) Abnormal neural synchrony in schizophrenia. J Neurosci 23:7407-7411.

Spencer KM, Nestor PG, Perlmutter R, Niznikiewicz MA, Klump MC, Frumin M, Shenton ME, McCarley RW (2004) Neural synchrony indexes disordered perception and cognition in schizophrenia. Proc Natl Acad Sci USA 101:17288-17293.

Sutherland GR, McNaughton B (2000) Memory trace reactivation in hippocampal and neocortical neuronal ensembles. Curr Opin Neurobiol 10:180-186.

Tekell JL, Hoffmann R, Hendrickse W, Greene RW, Rush AJ, Armitage R (2005) High frequency EEG activity during sleep: characteristics in schizophrenia and depression. Clin EEG Neurosci 36:25-35.

Tierney PL, Degenetais E, Thierry AM, Glowinski J, Gioanni Y (2004) Influ- 
ence of the hippocampus on interneurons of the rat prefrontal cortex. Eur J Neurosci 20:514-524.

Tomasulo RA, Ramirez JJ (1993) Activity-mediated changes in feedforward inhibition in the dentate commissural pathway: relationship to EPSP/spike dissociation in the converging perforant path. J Neurophysiol 69:165-173.

Tononi G, Edelman GM (2000) Schizophrenia and the mechanisms of conscious integration. Brain Res Brain Res Rev 31:391-400.

Tsodyks M (1999) Attractor neural network models of spatial maps in hippocampus. Hippocampus 9:481.

Uhlhaas PJ, Silverstein SM, Phillips WA, Lovell PG (2004) Evidence for impaired visual context processing in schizotypy with thought disorder. Schizophr Res 68:249-260.

van Vreeswijk C, Sompolinsky H (1998) Chaotic balanced state in a model of cortical circuits. Neural Comput 10:1321-1371.

von der Malsburg C (1981) The correlation theory of brain function. Tech- nical Report 81-2. Göttingen, Germany: Max Planck Institute for Biophysical Chemistry.

von der Malsburg C, Schneider W (1986) A neural cocktail-party processor. Biol Cybern 54:29-40.

Wesierska M, Dockery C, Fenton AA (2005) Beyond memory, navigation, and inhibition: behavioral evidence for hippocampus-dependent cognitive coordination in the rat. J Neurosci 25:2413-2419.

Wilson MA, McNaughton BL (1994) Reactivation of hippocampal ensemble memories during sleep. Science 265:676.

Zhuravin IA, Bures J (1991) Extent of the tetrodotoxin induced blockade examined by pupillary paralysis elicited by intracerebral injection of the drug. Exp Brain Res 83:687-690.

Zinyuk L, Kubik S, Kaminsky Y, Fenton AA, Bures J (2000) Understanding hippocampal activity by using purposeful behavior: place navigation induces place cell discharge in both task-relevant and task-irrelevant spatial reference frames. Proc Natl Acad Sci USA 97:3771-3776. 